\title{
Conservação das espécies vegetais em paleoambientes dunares na APA Dunas e Veredas do Baixo-Médio São Francisco, Bahia, Brasil
}

Apesar do avanço do conhecimento científico que se tem atualmente, com dados sobre a flora e sua respectiva distribuição, esse ainda não é completo e não permite que se prescinda da experiência de campo, intraduzível em termos de determinação da composição florística e características das plantas e do meio. Mediante tal pressuposto, este artigo objetiva demonstrar o levantamento das espécies vegetais realizado na Área de Proteção Ambiental (APA) Dunas e Veredas do Baixo-Médio São Francisco, e sua relevância para a manutenção do equilíbrio ecológico do paleo-ecossistema dunar. É possível afirmar que a vegetação é o espelho do clima e, sendo o espelho do clima, percebe-se que algumas espécies encontradas representam a fisionomia dos climas atuais, mas podendo indicar resquícios de paleoclimas. Desta maneira, a vegetação é vista coma à chave da manutenção do equilíbrio dinâmico do ecossistema e sua preservação é defendida por esta razão. Trata-se de uma pesquisa qualitativa e de cunho exploratório, onde fundamentou-se a priori em teóricos que abordam sobre tal temática e, em seguida utilizou-se o Método de Caminhamento introduzido por Filgueiras et al., (1994) sendo que, o uso deste, tem se mostrado eficiente para elaborar o levantamento qualitativo de grande parte da variabilidade florística em diferentes fitofisionomias. A pesquisa in loco possibilitou a identificação de várias espécies exóticas, endêmicas e, nativas da região semiárida, além de outras típicas de áreas mais úmidas (Floresta Amazônica, Floresta Atlântica e Áreas de Transições) Portanto, os resultados indicam a urgência da criação de planos estratégicos de conservação da diversidade florística da área dunar, tendo em vista que os vegetais ali presentes, são responsáveis pela estabilização das areias eólicas dos campos, e sem estas, consequentemente ter-se-á o agravamentos dos processos de degradação ambiental já evidente na área.

Palavras-chave: Conservação; Paleo-Ecossistemas; Dunas Fluviais.

\section{Conservation of plant species in dune paleoenvironments in APA Dunas e Veredas do Baixo-Médio São Francisco, Bahia, Brazil}

Despite the advancement of scientific knowledge we currently have, with data on the flora and its respective distribution, this is still not complete and does not allow that dispenses the field experience, untranslatable in terms of determining the floristic composition and characteristics of plants and the middle one. Through this assumption, this paper aims to demonstrate the lifting of plant species carried out in the Environmental Protection Area (APA) Dunes and Paths Lower-Middle, and its relevance for maintaining the ecological balance of the paleo-dune ecosystem. It is possible to say that the vegetation is the climate of the mirror and, if the mood of the mirror, it is clear that some species found represent the face of current climates, but may indicate traces of past climates. Thus, vegetation is seen with the key to maintaining the dynamic equilibrium of the ecosystem and its preservation is favored for this reason. This is a qualitative and exploratory research, where basing a priori theoretical addressing of such subject, and then used the Traverse method introduced by Filgueiras et al., (1994), and that the use of this, has proved efficient to develop the qualitative survey of much of the floristic variability in different vegetation types. The research on the spot enabled the identification of several exotic species, endemic and native to the semiarid region and other typical of more humid areas (Amazon Forest, the Atlantic Forest and Transition Areas). Therefore, the results indicate the urgency of creating strategic plans conservation of plant diversity in the dune area, considering that vegetables were present, are responsible for the stabilization of aeolian sand fields, and without these, consequently will have the aggravation of environmental degradation processes already evident in the area.

Keywords: Conservation; Paleo-Ecosystems; River Dunes.

Topic: Uso de Recursos Naturais

Reviewed anonymously in the process of blind peer.

Clecia Simone Gonçalves Rosa Pacheco

Instituto Federal do Sertão Pernambucano, Brasil http://lattes.cnpq.br/6358715394273386

clecia.pacheco@gmail.com

Niédja Maria Galvão Araújo e Oliveira Instituto de Tecnologia de Pernambuco, Brasil http://lattes.cnpq.br/3927952871639072 noliveira825@gmail.com
Received: 08/02/2016

Approved: 16/08/2016
Referencing this:

PACHECO, C. S. G. R.; OLIVEIRA, N. M. G. A.. Conservação das espécies vegetais em paleoambientes dunares na APA Dunas e Veredas do Baixo-Médio São Francisco, Bahia, Brasil. Natural Resources, v.6, n.1, p.6-17, 2016. DOI: http://doi.org/10.6008/SPC22379290.2016.001.0001 


\section{INTRODUÇÃO}

O clima de uma localidade é a síntese de todos os elementos climáticos em uma combinação de certa forma singular, determinada pelas interações dos controles e dos processos climatológicos. Por conta disso, sempre que a discussão estiver relacionada com espécies vegetais, existe a necessidade de classificação climática, visando à obtenção de um arranjo eficiente de informações em uma forma simplificada e ao mesmo tempo generalizada.

Neste sentido, a área da pesquisa segundo a classificação de Köppen, está caracterizada pelo clima $\mathrm{Bswh}^{1}$, possuindo precipitação anual em torno de $400-800 \mathrm{~mm}$, ocorrendo principalmente nos meses de outubro a março. Nesta área há o predomínio da vegetação de caatinga por conta dos solos arenosos pouco desenvolvidos das dunas e do clima semiárido (JACOMINE et al., 1976). Na concepção de Sá, Riché e Fotius (2003) os campos de dunas de Pilão Arcado até Barra, na Bahia, são extensas formações de depósitos eólicos, cuja altura pode ultrapassar os 100 metros. Os solos são bastante arenosos e possuem fertilidade natural muito baixa. Nas depressões interdunares, frequentemente, os solos têm características hídricas mais favoráveis (veredas). A vegetação é de caatinga hipoxerófila, com trechos de caatinga muito seca (hiperxerófila) na região de Pilão Arcado, Xique Xique e Barra, intercalada em alguns pontos por aspectos de caatinga úmida, densa e mais verde (hipoxerófila).

Partindo destes pressupostos iniciais, é relevante enfatizar que o objetivo dessa pesquisa não foi fazer um inventário das espécies vegetais do paleoambiente e, sim, da origem e composição atual da área dunar (climatologia, geologia, geomorfologia). Portanto, não se faz nesse trabalho um levantamento botânico das espécies existentes na área geral da pesquisa, mas apenas, um indicativo das espécies visualizadas e identificadas nos campos dunares visitados, por entender que são estas (as espécies vegetais), responsáveis pela estabilização das areias eólicas dos campos de dunas, sendo assim, vistas como importantes de serem qualificadas.

A metodologia utilizada foi o Método de Caminhamento de Filgueiras et al. (1994), que consiste basicamente em três etapas distintas: o reconhecimento das fitofisionomias, a elaboração da lista de espécies e a análise dos resultados levantados na pesquisa. $O$ referido método tem se mostrado bastante eficaz para a elaboração do levantamento qualitativo de grande parte da variabilidade florística em diferentes fitofisionomias paisagísticas. Utilizou-se também a abordagem ecodinâmica de Tricart (1977) visando classificar as espécies encontradas na área.

Portanto, foi possível identificar por meio do levantamento das espécies vegetais in loco, várias espécies exóticas, endêmicas e, nativas da região semiárida, além de outras espécies que são típicas de áreas mais úmidas, como por exemplo, de Floresta Amazônica, de Floresta Atlântica e de Áreas de Transição, que de acordo com pesquisas de Barreto (1996), estes enclaves de florestas úmidas penetraram na referida área de proteção ambiental (dunar), em paleo-épocas, através foz do rio Icatu, que é afluente do rio São Francisco.

${ }^{1}$ Semiárido quente com sete a oito meses de seca. 


\section{REVISÃO TEÓRICA}

\section{Flora do Bioma Caatinga Encontradas no Paleoambiente}

A Caatinga é, provavelmente, o bioma menos valorizado dos biomas brasileiros e, pouco conhecido botanicamente. Tal postura deriva de concepções equivocadas e que não cabe mais no meio científico, de que a Caatinga resulta da transformação de outra formação vegetal, estando agregada a uma diversidade muito baixa de plantas, sem espécies endêmicas e altamente degradadas por ações antropogênicas. Apesar de sofrer bastante com o processo de degradação, principalmente nas terras mais baixas, a Caatinga abarca uma diversidade de tipos vegetacionais, com grande número de espécies e também remanescentes de vegetação bastante preservada, compreendendo um número expressivo de táxons raros e endêmicos. (GIULIETTI et al., 2003).

Andrade- Lima $(1981,1989)$ chamou a atenção para o patrimônio da flora da Caatinga e salientou os exemplos exuberantes das adaptações das plantas aos hábitats semiáridos. Sendo assim, a Caatinga, tem se sobressaído por possuir uma elevada diversidade de espécies vegetais, muitas das quais endêmicas ao bioma, e outras que podem validar relações biogeográficas que auxiliam no esclarecimento da dinâmica histórica vegetacional da própria Caatinga e de todo o leste da América do Sul.

Na concepção de Souza et al. (2005) dois registros palinológicos revelam mudanças vegetacionais e climáticas da região da caatinga nordestina: o registro continental da caatinga do campo de dunas fósseis do médio rio São Francisco (BA) pesquisado por De Oliveira, Barreto e Suguio (1999) e o registro de sedimentos marinhos, obtido a cerca de $90 \mathrm{~km}$ ao leste da cidade de Fortaleza (CE), pesquisado por Behling et al. (2000).

O primeiro registro, que é de interesse dessa pesquisa, feito com sedimentos datados de 10.990 A.P. delata segundo a autora supracitada as condições climáticas muito diferentes das atuais.

Da transição Pleistoceno/Holoceno até cerca de 10.540 anos A.P., o clima da região era úmido e relativamente mais frio que o atual, favoreceu o estabelecimento de uma floresta tropical exuberante com afinidade florística com as florestas da Amazônia e as da Costa Atlântica. Os espectros polínicos desse período representam a primeira evidência botânica para o debatido corredor florestal entre a Amazônia e a floresta Atlântica, o que pode explicar a grande afinidade florística entre esses dois ecossistemas. Um gradual dissecamento da paisagem eliminou esse tipo de vegetação até cerca de 6.790 anos A. $P$. (SOUZA et al., 2005).

Mediante tal proposição, é possível afirmar que o estabelecimento da moderna vegetação de caatinga, conhecida no tempo presente, está datado no campo de dunas da Bahia em 4.535 anos A.P. de acordo com referenciação de Souza et al. (2005).

No entanto, de acordo com a obra "Classificação da Vegetação Brasileira Adaptada a um Sistema Universal" de autoria de Veloso, Rangel Filho e Lima (1991), a Região Florística Nordestina, denominada por estes - Savana Estépica - ou Caatinga do Sertão Semiárido é subdividida em três disjunções vegetacionais, a saber: Floresta Ombrófila Densa e Aberta; Floresta Estacional Semidecidual e Decidual e; Savana.

Estas referências justificam uma possível proeminência homogênea de dois tipos climáticos passados: um bastante antigo que revestia os planaltos com altitudes mais elevadas que os seus atuais resíduos, durante todo o Paleozóico até o fim do Mesozóico e, outro considerado mais recente, iniciado no 
final do Cretáceo e concluído no final do Pliopleistoceno, quando provavelmente ocorreram os depósitos fossilíferos de plantas Angiospermas demonstrando o atual quadro florístico da região nordestina. (VELOSO; RANGEL FILHO; LIMA, 1991)

Esta região florística é eminentemente climática nos tempos atuais, com áreas pluviais de superúmidas as úmidas na costa florestal atlântica até o território árido interiorano da Savana Estépida (caatingas do Sertão árido), passando por trechos subúmidos do chamado "agreste florestal estacional" situado entre os extremos climáticos, porém, com florística típica. (VELOSO; RANGEL FILHO; LIMA, 1991)

Com base nessas inferências, é factível subdividir o Nordeste em faixas florestais, onde a primeira faixa florestal é denominada de Zona da Mata, a segunda de Zona do Agreste e a terceira faixa florestal, que é de fato a que interessa a este estudo é chamada de Zona do Sertão, apresentando uma florística endêmica própria de climas semiáridos e áridos, com chuvas descontínuas torrenciais seguidas por longo período seco que pode durar alguns anos.

Segundo Veloso et al. (1991) o tipo de vegetação que se instala nessa zona é a savinícola, com predominância de plantas espinhosas deciduais, que, embora estabelecidas dentro do espaço intertropical sul, apresenta uma florística homóloga das áreas estépicas dos climas temperados pré-andinos da Argentina e Bolívia.

Os autores supracitados procuram fazer uma comparação nas espécies existentes no Sertão Semiárido com espécies encontradas em outras partes da América do Sul e, encontram diversas similaridades. Mencionam por exemplo à família Neotropical Cactáceae de provável origem no território andino sul americano, apresenta-se na Savana Estépida Cereus jamacuru ochlospécie frequente em todas as áreas deste tipo de vegetação e, mais ecótipos dos gêneros Pilocereus, Pereskia e Melocactus que imprimem à vegetação um caráter ímpar na fisionomia ecológica dessa região.

Além da família Cactáceas, outras ochlospécies ${ }^{2}$ caracterizam este tipo de vegetação, como por exemplo, Amburana cearensis, com duas variedades, a A. cearensis var cearensis, com ocorrência na província de Saltos na Argentina e por todo o Sertão nordestino, no Brasil e, A. cearensis var acreana, frequente na Amazônia Ocidental [...]. Copernicia prunifera com duas variedades a C. prunifera var cerifera ocorrendo em toda área do Sertão do Nordeste, principalmente nos vales e áreas alagadas temporariamente, e $C$. prunifera var australis frequente na denominada "savana úmida" do "Chaco boreal", ocorrendo no Pantanal Matogrossense do extremo sul. (VELOSO et al., 1991)

Ainda na concepção dos autores supracitados, além destas espécies mencionadas, consideradas típicas e características da Savana Estépica, demonstram ligações filogenéticas indiscutíveis entre essas áreas separadas geograficamente, outros ecótipos com diferenças fenotípicas que mostram grande identidade genotípica entre os seguintes gêneros:

a) Zizyphus mistrol no Chaco Mato-grossense do Sul e no Parque de Espinilho do Rio Grande do Sul e no Sertão Nordestino;

b) Prosopis algarobilla no Chaco Mato-grossense do Sul e no Parque de Espinilho do Rio Grande do Sul e, P. ruscifolia no Sertão Nordestino;

\footnotetext{
${ }^{2}$ Espécies que apresenta ampla distribuição geográfica e, que exibe ao longo de sua área de ocorrência uma uniformidade morfológica relativamente grande. (http://portugues.free-ebooks.net)
} 
c) Schinopsis brasiliensis no Chaco Mato-grossense do Sul, com variedades e, S. brasiliensis no Brasil Central até o Sertão Nordestino e muitas outras espécies.

São estes exemplos mais típicos que mostram as semelhanças florísticas entre essas áreas tidas como distintas disjuntas, mas fitogeograficamente similares. Sendo assim, constata-se que esta região florística apresenta duas linhas fitogenéticas diferentes, sendo uma australásica andina e outra, afro-amazônica que se mesclam no Nordeste brasileiro para formarem um domínio florístico brasileiro nordestino, com inúmeros ecótipos endêmicos (VELOSO; RANGEL FILHO; LIMA, 1991).

\section{METODOLOGIA}

\section{Localização da Área}

A área de estudo está localizada dentro da APA Dunas e Veredas do Baixo-Médio São Francisco situada entre as coordenadas geográficas $10^{\circ} 48^{\prime} 59^{\prime \prime} \mathrm{S} ; 42^{\circ} 52^{\prime} 32^{\prime \prime} \mathrm{W}$ e, 110.1'20”S; 430.'10” W, em terrenos dos municípios de Barra e Xique Xique no Estado da Bahia/Brasil (figura 1).

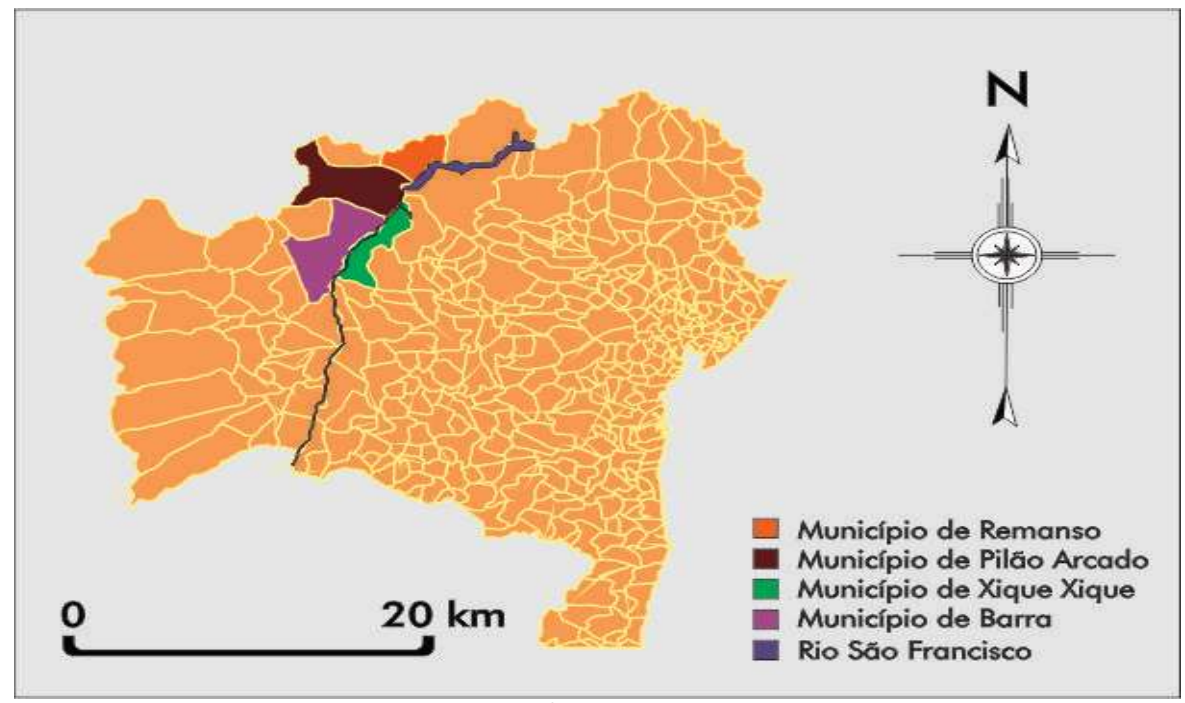

Figura 1: Área da Pesquisa.

\section{O Método de Caminhamento e a Abordagem Ecodinâmica da Paisagem}

O método de caminhamento foi introduzido por Filgueiras et al. (1994) e, o uso deste tem se mostrado eficiente para elaborar o levantamento qualitativo de grande parte da variabilidade florística em diferentes fitofisionomias. Tal método consiste basicamente em três etapas distintas, a saber:

a) Reconhecimento das fitofisionomias, onde, para cada tipo fisionômico, deverão ser observadas as topografias do terreno, suas classes de solo (s), altura média das árvores, presença ou não de dossel, de árvores emergentes com estimativas de altura, presença ou ausência de sub-bosque com sua altura se presente, presença ou ausência da camada rasteira com sua altura se presente, estado de preservação da área, presença ou não de plantas invasoras e demais observações pertinentes;

b) Lista das espécies, onde, para cada tipo fisionômico reconhecido, traçam-se linhas imaginárias ao longo da área, no sentido do maior comprimento, que são percorridos anotando-se o nome comum e posteriormente o nome científico, o hábito e o número de indivíduos de todas as espécies encontradas ao longo do trajeto. Essas espécies serão posteriormente agrupadas nas categorias de (F) - Frequente (espécies com 
número de indivíduos igual ou superior a $10 \%$ dos indivíduos avistados nas linhas de amostragem), (C) - Comum (5 a 9\%), (O) - Ocasional (1 e 4,9\%) e (LR) Localmente Rara (menos de 1\%);

Análise dos resultados, que consistiu na organização dos dados obtidos e na elaboração de tabelas, gráficos e listas de espécies, que facilitará o entendimento do leitor no que tange à temática em tese.

Durante as visitas efetuadas em campo foi feito o levantamento quali-quantitativo das espécies nativas do bioma caatinga ainda encontradas no paleoambiente consistindo basicamente na descrição sumária da vegetação da área amostral, a partir do método de "caminhamento", já mencionado. Para cada tipo de vegetação foi construída uma tabela sinótica discorrendo as seguintes características: espécie; família; nome vulgar; quantidade encontrada; altura média das espécies; foto; ambiente vegetacional onde as mesmas estão inseridas (Floresta ciliar de carnaúba, Caatinga hiperxerófila, Caatinga hipoxerófila, Vegetação de transição e Vegetação de veredas); agrupamento (frequente, comum, ocasional e localmente rara); e, por fim o estado de conservação de acordo com o Método Ecodinâmico de Tricart (1977), classificando-as em estáveis, intergrades e instáveis.

Quanto à classificação das espécies e suas respectivas famílias utilizou-se como embasamento as nomenclaturas descritas por Ribeiro (2010) em sua obra: algumas espécies de plantas reunidas por famílias e sua propriedade; Gariglio et al., (2010) em seu trabalho intitulado - Uso sustentável e conservação dos recursos florestais da caatinga; e, Castro e Cavalcante (2010), no livro - Flores da caatinga = Caatinga flowers.

Assim sendo, a vegetação predominante na área é do tipo caatinga, subdividindo-se em hiperxerófila (caatinga arbustiva) e hipoxerófila (caatinga arbórea). No caso da vegetação hiperxerófila, esta é encontrada geralmente, próximo ao rio São Francisco, exibindo aspecto rasteiro e aberto, variando de densidade. Essa premissa de Jacomine et al (1976) foi constatada in loco conforme descrição abaixo, sendo que as espécies estão discriminadas de acordo com a tabela a seguir (Quadro 1).

Quadro 1: Quadro de distribuição de espécies hiperxerófila.

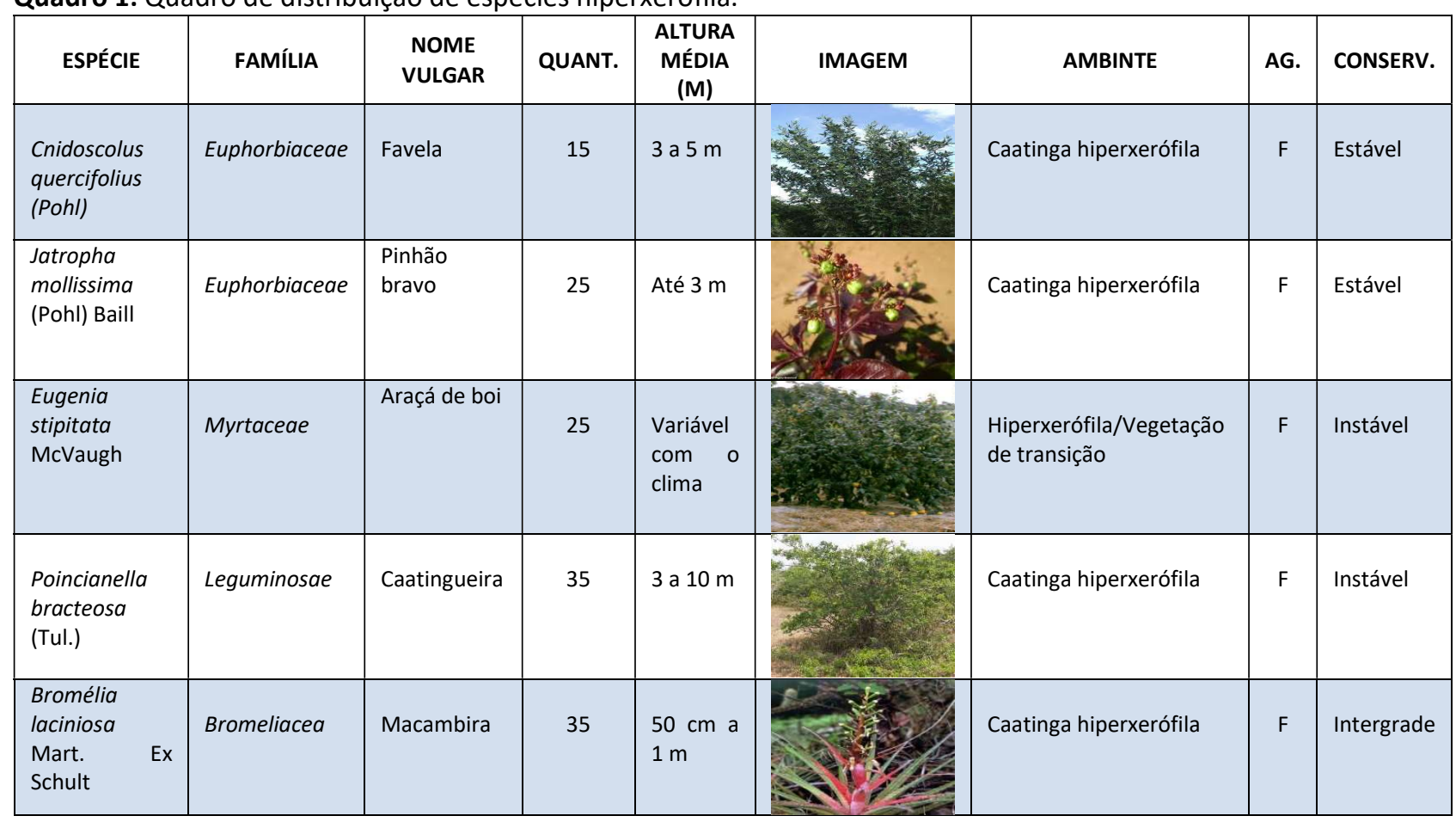




\begin{tabular}{|l|l|l|l|l|l|l|}
\hline $\begin{array}{l}\text { Tacinga } \\
\text { inamoena (K. } \\
\text { Schum) N. P. }\end{array}$ & Cactaceae & Quipá & 12 & $4 \mathrm{~cm}$ & Caatinga hiperxerófila \\
$\begin{array}{l}\text { Taylor e } \\
\text { Stuppy }\end{array}$ & $\begin{array}{l}\text { Malva } \\
\text { parviflora L. } \\
\text { (N. P. Taylor e } \\
\text { Stuppy) }\end{array}$ & Malvaceae & $\begin{array}{l}\text { Malva de } \\
\text { garrote }\end{array}$ & 28 & $\begin{array}{l}0,50 \mathrm{~cm} \\
\mathrm{a} 1 \mathrm{~m}\end{array}$ & Estável \\
\hline
\end{tabular}

Caatinga é uma expressão que se refere ao aspecto típico da região nordestina, com clima árido e semiárido, notadamente apresentando uma estação seca, em que a maioria das árvores perde as folhas e os troncos esbranquiçados e secos domina a paisagem (CORTEZ; CORTEZ, 2007). Enquanto vegetação apresenta três estratos: arbóreo ( 8 a $12 \mathrm{~m}$ ), arbustivo ( 2 a $5 \mathrm{~m}$ ) e herbáceo (abaixo de $2 \mathrm{~m}$ ). As características da vegetação revelam várias adaptações à sobrevivência em clima árido e seco. As folhas, por exemplo, costumam ser pequenas, podendo inclusive não possuir a aparência normal de folhas (os cactos são exemplos, cujos espinhos são folhas modificadas). Algumas plantas armazenam água em caules suculentos (típicos dos cactos), enquanto outras se caracterizam por terem raízes tipicamente na superfície do solo, o que favorece o máximo de absorção de água em período chuvoso (CORTEZ; CORTEZ, 2007).

Entre as plantas típicas deste bioma, podemos citar: facheiro, juazeiro, mandacaru, catingueira, faveleira, marmeleiro, aroeira, carnaúba, xiquexique, barriguda, mulambá, jatobá, amburana, umbu, baraúna, macambira e maniçoba (Ibid., 21).

Portanto, a caatinga hipoxerófila ocorre na extensão e sobre os depósitos de areias eólicas e é semelhante a uma vegetação de transição entre a caatinga e a Floresta Caducifólia. As espécies visualizadas estão distribuídas na tabela a seguir (Quadro 2).

Quadro 2: Quadro de distribuição de espécies hipoxerófilas.

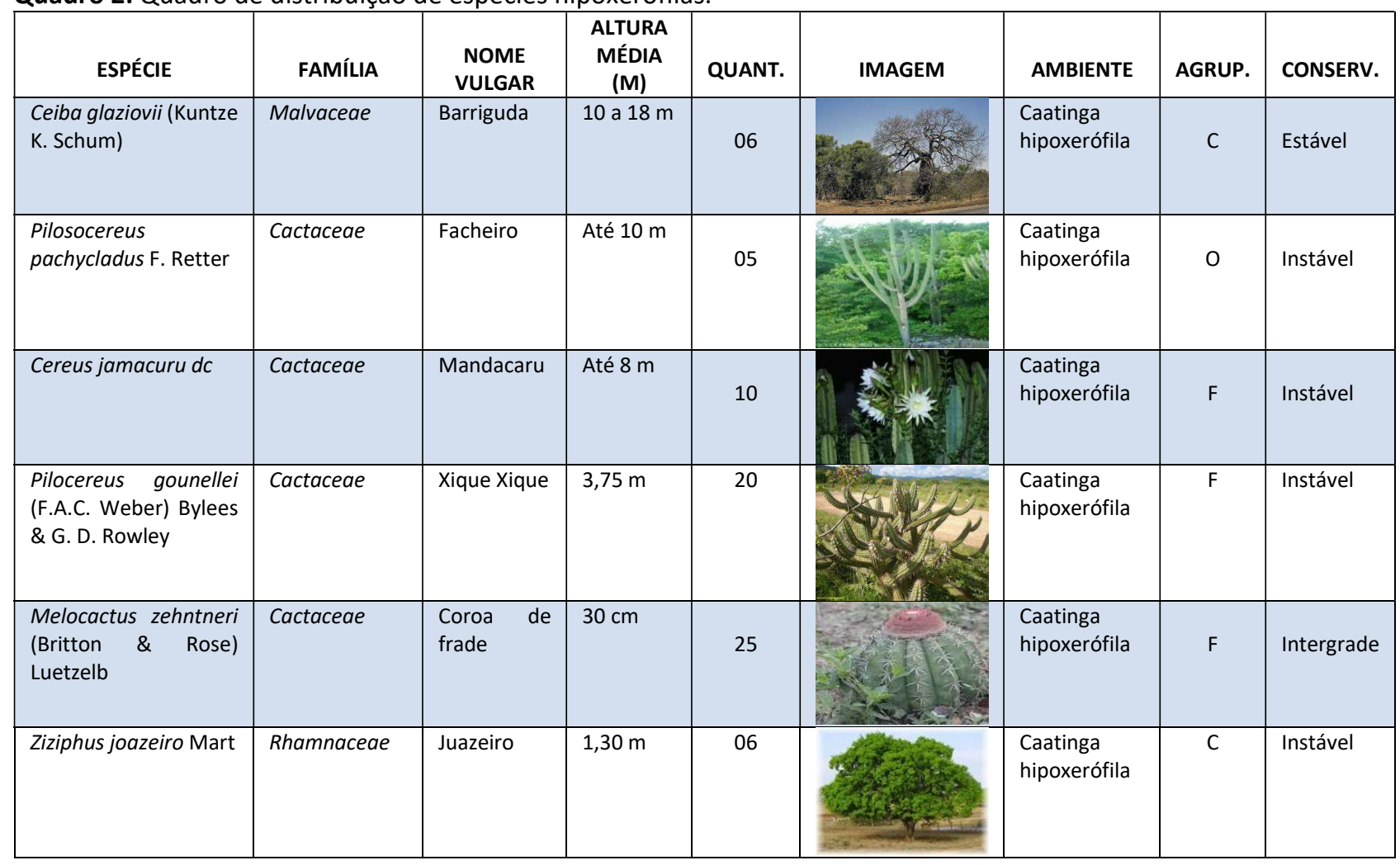




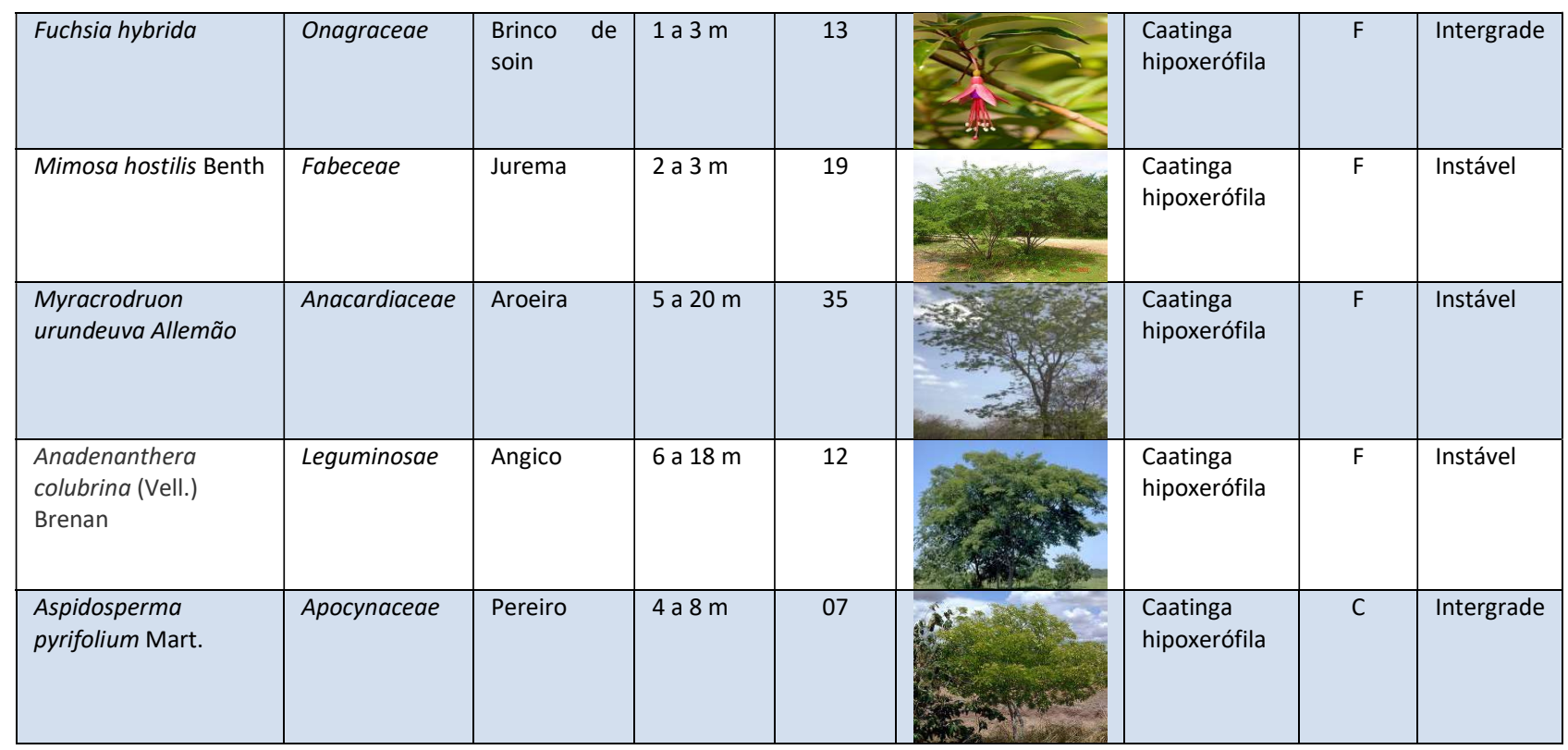

Além das espécies já descritas, circundando ou margeando o São Francisco, é possível encontrar uma Floresta Ciliar de Carnaúba (FCC), com diversas espécies, especificadas na tabela abaixo (Quadro 3).

Quadro 3: Quadro de distribuição de espécies FCC.

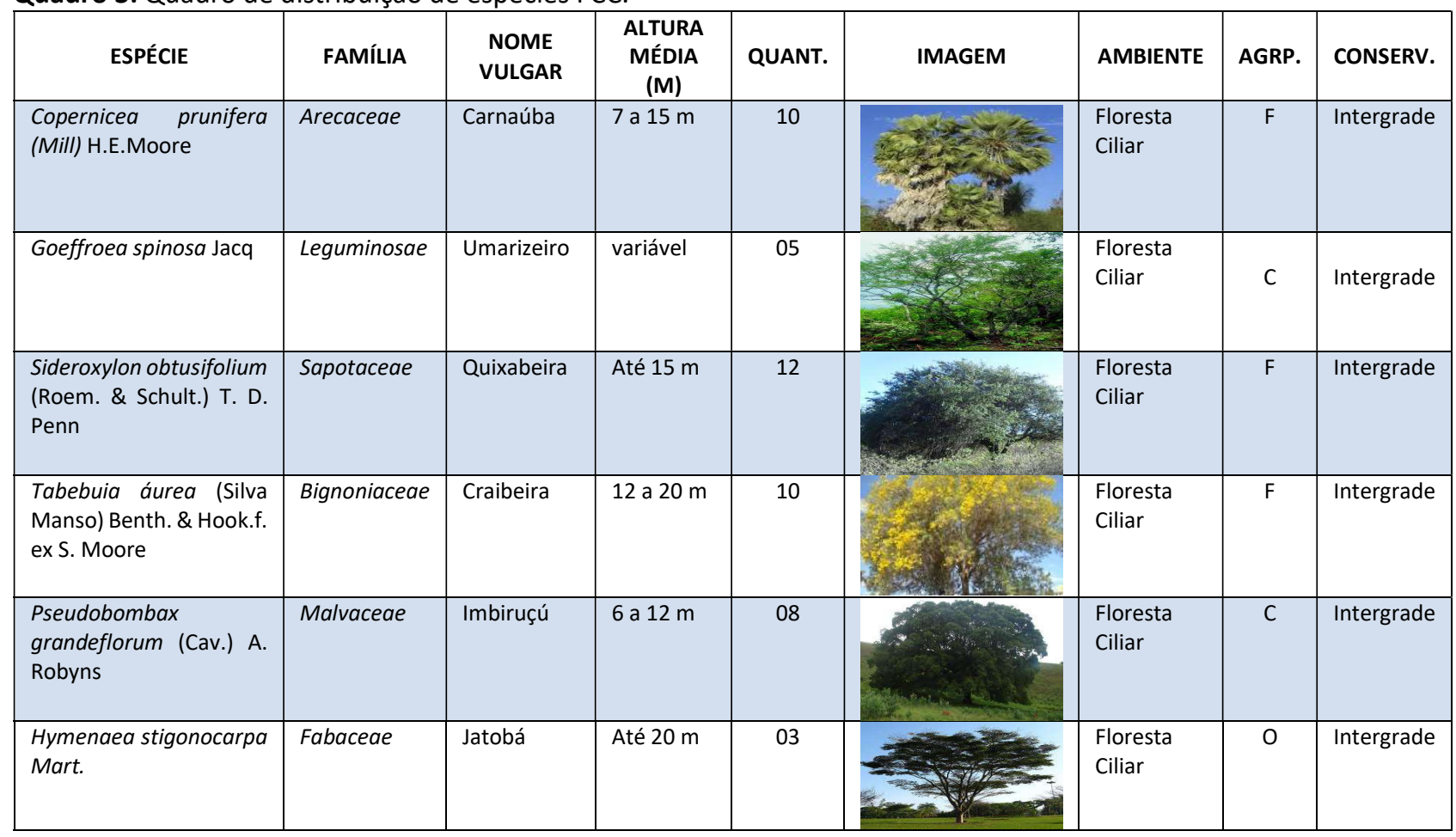

Nas áreas interdunares identificou-se espécies que Jacomine et al. (1976) intitula de vegetação típica de veredas desenvolvidas em solos hidromórficos, distribuídas na tabela a seguir (Quadro 4) e, denominada de acordo com a seguinte descrição.

Quadro 4: Quadro de distribuição de espécies de veredas interdunares.

\begin{tabular}{|c|c|c|c|c|c|c|c|c|}
\hline ESPÉCIE & FAMÍLIA & $\begin{array}{c}\text { NOME } \\
\text { VULGAR }\end{array}$ & $\begin{array}{c}\text { ALTURA } \\
\text { MÉDIA (M) }\end{array}$ & QUANT. & IMAGEM & AMBIENTE & AGRUPTo & CONSERV. \\
\hline
\end{tabular}




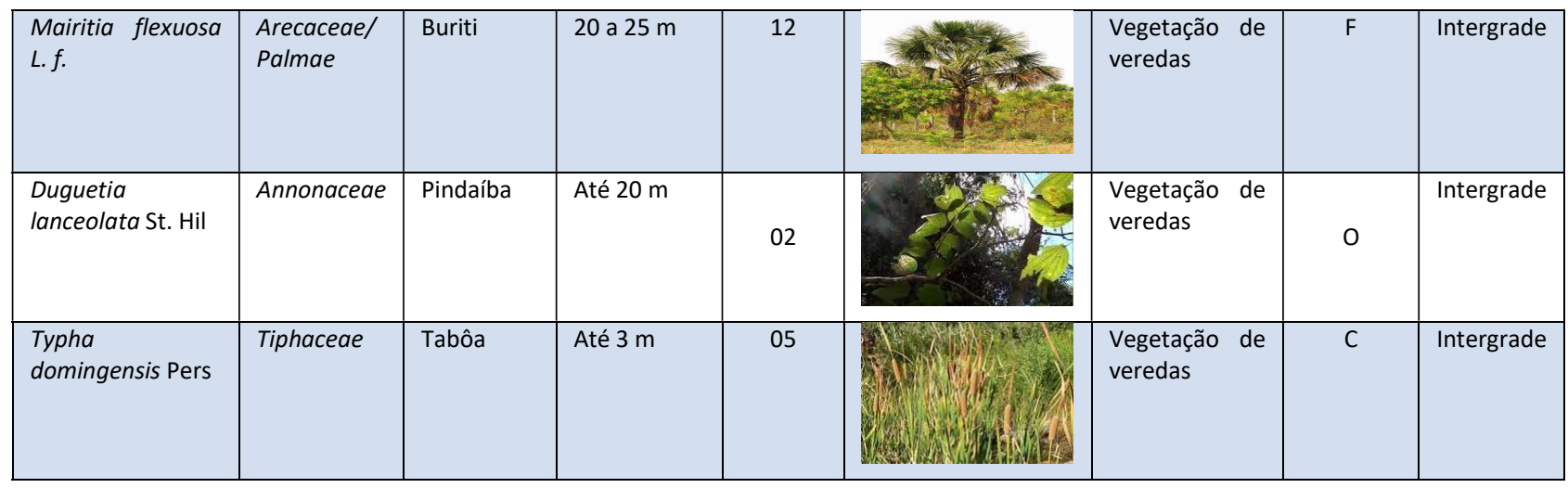

Entretanto, de acordo com as subdivisões de Andrade-Lima (1956) em sua obra "Estudos Fitogeográficos de Pernambuco" a área por ele denominada de Sertão do São Francisco se caracteriza mais pela fisionomia que mesmo pela variação das espécies, comparando-a com o sertão central. Segundo ele, a vegetação é mais escassa e de um modo geral mais baixa. Algumas espécies ocorrem de preferência nesta região, dentre as quais se destacam a Palmae - a Carnaubeira - (Copernicea cerifera Mart) já mencionada anteriormente e, encontrada na área da pesquisa. Além desta, destaca-se as seguintes Leguminosae no quadro a seguir (Quadro 5).

Quadro 5: Quadro de distribuição de espécies Fabaceae.

\begin{tabular}{|c|c|c|c|c|c|c|c|c|}
\hline ESPÉCIE & FAMÍLIA & $\begin{array}{l}\text { NOME } \\
\text { VULGAR }\end{array}$ & $\begin{array}{l}\text { ALTURA } \\
\text { MÉDIA } \\
\text { (M) }\end{array}$ & QUANT. & IMAGEM & AMBIENTE & AGRUPTo & CONSERV. \\
\hline $\begin{array}{l}\text { Senna spectabilis } \\
\text { (DC.) h. S. Irwing \& } \\
\text { Barneby }\end{array}$ & Leguminosae & Canafístula & 4 a $6 \mathrm{~m}$ & 13 & & $\begin{array}{l}\text { Caatinga } \\
\text { hipoxerófila }\end{array}$ & $F$ & Instável \\
\hline $\begin{array}{l}\text { Pithecolobium } \\
\text { diversifolium Benth }\end{array}$ & Fabaceae & Carcarazeiro & 2 a $5 \mathrm{~m}$ & 03 & & $\begin{array}{l}\text { Caatinga } \\
\text { hipoxerófila }\end{array}$ & $\mathrm{O}$ & Intergrade \\
\hline $\begin{array}{l}\text { Bauhinia pentandra } \\
\text { (Bong.) D. Dietr }\end{array}$ & Caesalpinaceae & Mororó & Até $2 \mathrm{~m}$ & 05 & & $\begin{array}{l}\text { Caatinga } \\
\text { hipoxerófila }\end{array}$ & 0 & Intergrade \\
\hline
\end{tabular}

\section{RESULTADOS E DISCUSSÕES}

Buscou-se nesse trabalho discorrer sobre o levantamento das espécies encontradas na área da pesquisa, fundamentando tais achados em teóricos que discutem sobre a temática. É primordial dizer que a vegetação reflete o clima e, sendo assim, percebeu-se que algumas espécies encontradas representam a fisionomia dos climas atuais, mas podendo indicar resquícios de paleoclimas.

Sendo assim, é crucial enfatizar que a vegetação dos paleoambientes pesquisados, se adaptam, sobretudo, as elevadas temperaturas, porque são compostas, em sua maioria, de plantas xerófitas. Desta forma, pode-se afirmar que no Sertão a vegetação sofre com a seca física e por conta disso se desenvolvem as espécies de bromélias, cactáceas entre outras, que também são encontradas em dunas costeiras. No entanto, nas dunas costeiras a vegetação sofre com a seca fisiológica, pois apesar de possuir água, esta é bastante salobra.

Porém, foi possível identificar várias espécies exóticas, endêmicas e, nativas da região semiárida (conforme descritas nos quadros anteriores), além de outras típicas de áreas mais úmidas (Floresta 
Amazônica, Floresta Atlântica e de áreas de transição), que segundo estudos de Barreto (1996), estes enclaves de florestas úmidas penetraram, em paleoépocas, na área dunar pela foz do rio Icatu, que é afluente do rio São Francisco. Outrossim, as espécies encontradas nas dunas são geralmente as mesmas encontradas em seu entorno, variando apenas nas dunas que possuem suas bordas banhadas pelas águas do rio São Francisco, onde nesses trechos, a vegetação é ciliar e, portanto, mais densa e verde.

As denominadas caatingas de areia, assim como os carrascos, possuem porte não muito distinto das caatingas mais típicas do cristalino. Em áreas mais favoráveis tem porte mais alto, menor densidade de lenhosas e de herbáceas, formando matas secas (LIMA et al., 2007).

Estudos de Rodal e Sampaio (2002) analisaram as implicações das diferentes descrições e delimitações de caatinga e identificaram três características básicas, na maioria dos escritos: (i) a vegetação que cobre uma área grande e mais ou menos continua, no Nordeste do Brasil, submetida a um clima semiárido, bordejada por áreas de clima mais úmido; (ii) a vegetação desta área, com plantas que apresentam características relacionadas à adaptação a deficiência hídrica (caducifólia, herbáceas anuais, suculência, acúleos e espinhos, predominância de arbustos e arvores de pequeno porte, cobertura descontinua de copas); e (iii) a vegetação com algumas espécies endêmicas a esta área semi-arida e com algumas espécies que ocorrem nesta área e em outras áreas secas mais distantes, mas não nas áreas circunvizinhas.

Superposta a toda essa variação natural descrita anteriormente, existe a repercussão da ocupação humana. Quase toda a vegetação das áreas mais úmidas (veredas, sopés de serra úmidos, margem fluvial, etc.) cedeu lugar a plantações ou abertura de pastos. Nas encostas mais secas, a agricultura itinerante vem criando um mosaico de parcelas com distintos tempos de regeneração, durante a fase de pousio e no intervalo das roças (GARIGLIO, et al., 2010).

Historicamente, a Caatinga sofreu impactos do processo de uso e ocupação do solo, que a degradaram paulatinamente. Tal degradação é influenciada pela predisposição geoambiental e pela ação do homem, pois a ocupação desordenada agravou os impactos. A vegetação de caatinga passou a ser usada como fonte de energia em domicílios, em olarias, em casas de farinha, em padarias, em indústrias do gesso, em fábricas de cimento e de siderurgias. A pecuária extensiva, o extrativismo insustentável e a agricultura de baixa tecnologia também contribuíram fortemente para esta transformação (SOUZA, 2006).

De acordo com Trindade (1991), quando não há cobertura vegetal nos campos dunares, estes ficam susceptíveis à ação eólica, deslocando-se e causando inconvenientes junto a comunidades do entorno das áreas situadas na mesma linha de ação dos ventos, uma vez que acaba soterrando tudo por onde passam, alterando o relevo, deixando uma cobertura quartzosa improdutiva e transformando a paisagem costeira.

Tais ecossistemas se diferenciam por ser sumariamente explorados economicamente, para os mais diversos fins como habitação, retirada de areias para construção e para solapamento de estradas e rodagens, turismo, entre outros aspectos que evoluem sobre a paisagem fragilizada, expondo risco tanto para a natureza, quanto a população ali residente, gerando diversos impactos ambientais. 
Mediante tal realidade e a interdependência de tais ecossistemas, de imponderável valor e pertinência ambiental, em face de sua transcendente produtividade biológica e notável estado de preservação, requer um gerenciamento que contemple estes múltiplos componentes da paisagem dunar.

Sendo assim, de acordo com a Resolução do CONAMA supracitada, as APA's devem possuir um zoneamento ecológico-econômico visando estabelecer normas de uso de acordo com as condições bióticas, geológicas, urbanísticas, agropastoris, extrativistas, culturais e outras, objetivando maior equilíbrio e conservação da área.

Portanto, as atividades antrópicas, da maneira como são desenvolvidas nos dias atuais, não são compatíveis com as condições ambientais e nem com o regime pluviométrico da região em tese (as paleodunas da Caatinga), o que amplia ainda mais os níveis de fragilidades destes ecossistemas, acarretando a degradação contínua e a extinção de espécies endêmicas desse/neste bioma.

\section{CONSIDERAÇÕES FINAIS}

O presente estudo procurou discorrer sobre a identificação das espécies florísticas dos campos de paleodunas e das áreas interdunares, visando analisar se as espécies encontradas nas dunas são as mesmas encontradas no seu entorno e, se há alguma evidencia de espécies da flora dessa área que tenha similaridade com a flora costeira.

As áreas de vegetação mais preservada são poucas, fragmentadas e geralmente localizadas nos pontos mais inacessíveis. As Unidades de Conservação apesar de ultimamente terem aumentado em quantidade, são relativamente pequenas ou não fiscalizadas ou mal gerenciadas, sendo que as de uso indireto cobrem uma pequena fração da área original e estão concentradas em algumas das ecorregiões. As áreas de cristalino da depressão sertaneja são especialmente mal cobertas por Unidades de Conservação.

Compreendeu-se, portanto, que o poder público confere pouca proteção ao bioma Caatinga na forma de Unidades de Conservação, principalmente as de Proteção Integral. Esse é um dos pontos mais abordados na literatura e foi comprovado pela pesquisa em campo. Além disso, boa parte das Unidades de Conservação de Uso Sustentável ocorre sob a categoria de Áreas de Proteção Ambiental, que, concretamente, confere pouca proteção e, além disso, não possuem uma política estratégica no que tange à gestão e ordenamento territorial da área.

\section{REFERÊNCIAS}

ANDRADE-LIMA, D.. Estudos fitogeográficos de Pernambuco. Instituto de Pesquisas Agronômicas de Pernambuco, Recife. 1957, 41p. (Nova série, 2) ANDRADE-LIMA, D. The caatingas dominium. Revista Brasileira de Botânica, v. 4, p. 149-163, 1981.

ANDRADE-LIMA, D.. Plantas das caatingas. Rio de Janeiro: Academia Brasileira de Ciencias, 1989. 243 p.

BARRETO, A. M. F.. Interpretação paleoambiental do sistema de dunas fixadas do médio Rio São Francisco,
Bahia. Instituto de Geociências, Universidade de São Paulo, São Paulo: Tese de Doutoramento, 1996, 174 p.

BEHLING, H.; NEGRET, A. J.; HOOGHIEMSTRA, H.. Holocene Amazon rainforest-savanna dynamics and climatic implications: high-resolution pollen record from Laguna Loma Linda in eastern Colombia. Journal of Quaternary Science, v. 15, n. 7, p. 687-695. 2000

CASTRO, A. S.; CAVALCANTE, A.. Flores da caatinga = Caatinga flowers. Campina Grande/PB: Instituto Nacional do Semiárido, 2010. 
CONSELHO NACIONAL DO MEIO AMBIENTE. Resoluções do Conama: Resoluções vigentes publicadas entre setembro de 1984 e janeiro de 2012. / Ministério do Meio Ambiente. Brasília: MMA, 2012. 1126 p.

CORTEZ, J. S.. Caatinga. São Paulo: HARBRA, 2007. Coleção Biomas do Brasil.

FILGUEIRAS, T. S., BROCHADO, A. L., NOGUEIRA, P. E.; GUALLA II, G. F.. Caminhamento - Um método expedito para levantamentos florísticos qualitativos. In: Caderno de Geociência IBGE. 1994, 12: 39-43.

GARIGLIO, M. A.; SAMPAIO, E. V. de S. B.; CESTARO, L. A.; KAGEYAMA, P. Y.. Uso sustentável e conservação dos recursos florestais da caatinga. Brasília: Serviço Florestal Brasileiro, 2010. 368p.

GIULIETTI, A. M.; BOCAGE NETA, A. L.; CASTRO, A. A. J. F.; VIRGINIO, J. F.; SAMPAIO, E. V. S. B.; GAMARRA-ROJAS, C. F. L.; QUEIROZ, L. P.; FIGUEIREDO, M. A.; RODAL, M. J. N.; BARBOSA, M. R. V.; HARLEY, R. M.. Diagnóstico da vegetação nativa do Bioma Caatinga, Brasil. Brasília: MMA; Recife: UFPE, 2004.

JACOMINE, P. K. T.; CAVALCANTE, A.C.; RIBEIRO, M. R.; MONTENEGRO, J. O.; BURGOS, N.. Levantamento Exploratório- Reconhecimento de solos da margem esquerda do Rio São Francisco, Estado da Bahia. Boletim Técnico EMBRAPA, n.38, p.404, 1976.

LIMA, J. R.; SAMPAIO, E. V. S. B.; RODAL, M. J. N.; ARAÚJO, F. S.. Estrutura da floresta estacional decidual montana (mata seca) da RPPN Serra das Almas, Ceará. Revista Brasileira de Biociências, v.5, p.438-440, 2007.

RODAL, M. J. N.; SAMPAIO, E. V. S. B.. A vegetação do bioma caatinga. In: SAMPAIO, E. V. S. B.; GIULIETTI, A. M.; VIRGINIO, J.; GAMARRA-ROJAS, C. F. L.. Vegetação e flora da caatinga. Recife: PNE/CNIP, 2002. p.11-24

SÁ, I. B.; RICHÉ, G. R.; FOTIUS, G. A.. As paisagens e o processo de degradação do Semiárido nordestino. In: SILVA, J. M. C.; TABARELLI, M.; FONSECA, M. T.; LINS, L. V.. Biodiversidade da Caatinga: áreas e ações prioritárias para a conservação. Brasília: MMA; Recife: UFPE, 2003.

SOUZA, C. R. G.; SUGUIO, K.; OLIVEIRA, A. M. S.; OLIVEIRA, P. E.. Quaternário do Brasil. Ribeirão Preto: Holos, 2005.

SOUZA, M. J. N.. A problemática ambiental: cenários para o Bioma Caatinga no Nordeste do Brasil. In: SILVA, J. B.; LIMA, L. C.; DANTAS, E. W. C.. Panorama da Geografia Brasileira, São Paulo, v.2, p.119-133, 2006.

TRICART, J.. Ecodinâmica. Rio de Janeiro: IBGE-SUPREN, 1977.

TRINDADE, A.. Estudo florístico e fitossociológico do estrato arbustivo-arbóreo de um trecho da floresta arenícula costeira do Parque Estadual das Dunas, Natal, RN. Recife: 1991.

VELOSO, H. P., RANGEL-FILHO, A. L. R.; LIMA, J. C. A.. Classificação da vegetação brasileira adaptada a um sistema universal. Rio de Janeiro: IBGE, 1991. 